\title{
Developing a health surveillance strategy for professional footballers in compliance with UK health and safety legislation
}

\author{
Colin W Fuller, Richard D Hawkins
}

\begin{abstract}
The need for health surveillance for professional footballers has been assessed against criteria specified in UK health and safety legislation. As footballers suffer from chronic injuries under normal playing conditions, professional football clubs have a requirement to implement health surveillance programmes to protect their players. A health surveillance programme, based on benchmarking a player's fitness and addressing the issues of pre-recruitment, pre-season, duringseason, post-season, and rehabilitation assessment, is proposed.

(Br F Sports Med 1997;31:148-149)
\end{abstract}

Keywords: football; health surveillance; legislation

In cases of acute injury, the majority of sportspeople recover and return to their sport and enjoy a continuing career. Other sportspeople, though, are forced to retire because of chronic injuries caused by their long term participation in sport. Many chronic injuries to certain muscles, tendons, and joints are the consequence of overuse or overload. These injuries are frequently the result of repetitive micro-trauma gradually deteriorating with continued untreated use. The epidemiology and aetiology of chronic injuries in sport have been reviewed by Renstrom. ${ }^{1}$

Current health and safety legislation in the UK is an effective way of ensuring that people at work are protected from potential hazards and that the risks to their health and safety are understood and controlled via the process of risk assessment. Fuller ${ }^{2}$ highlighted the fact that many professional sportspeople are employees and as such are covered by the same health and safety legislation as other workers. In this context, there is a requirement, under Regulation 5 of the Management of Health and Safety at Work (MHSAW) Regulations 1992, ${ }^{3}$ for employers to ensure that, where appropriate, health surveillance is provided for employees so that risks to their health are minimised. Although there is a lack of data, it is generally acknowledged that many sportspeople are forced to retire as a consequence of chronic health conditions. Professional footballers are at risk in this respect, so potential health hazards should be identified and, if appropriate, health surveillance strategies should be developed to monitor and minimise the risks to players.

\section{Discussion}

Health surveillance in the context of health and safety legislation has a much broader definition than in a purely occupational health context as it is used to ensure the fitness of employees to do their job and to detect adverse effects at an early stage. The Health and Safety Executive have set out four criteria for introducing health surveillance for employees in the Approved Code of Practice for the MHSAW Regulations. $^{3}$ To determine whether health surveillance is required for professional footballers, it is necessary to address these criteria.

IDENTIFIABLE ADVERSE HEALTH CONDITIONS ASSOCIATED WITH NORMAL ACTIVITIES EXIST Routine activities for footballers during practice and competition include running, jumping, turning, kicking, tackling, and heading; these activities could lead to injury to a player's foot, ankle, leg, knee, thigh, groin, back, and head. Ekstrand ${ }^{4}$ has reviewed the epidemiological and aetiological data available on football injuries and his work confirms that many chronic injuries do occur in football.

THERE IS A REASONABLE LIKELIHOOD THAT THE ADVERSE HEALTH CONDITIONS OCCUR UNDER THE CONDITIONS OF WORK

Effective control measures, such as fitness training, physiotherapy, medical support, and information, help to prevent or minimise injury. However, around $2 \%$ of professional footballers are claimed to retire each year through injury ${ }^{5}$; some of these are related to chronic injuries. Hodson ${ }^{6}$ also reported a high level of overuse injuries found in young players seeking entry to the Football Association's School of Excellence. Overuse injuries that go undiagnosed and/or untreated can lead to chronic injuries and this gives particular concern with younger players. 
VALID TECHNIQUES ARE AVAILABLE TO DETECT INDICATIONS OF THE ADVERSE HEALTH CONDITIONS

There are many techniques available for identifying adverse health conditions in footballers. ${ }^{1}$ For routine purposes, tests for measuring muscle strength and the range of movement in ankle, knee, and hip joints indicate impaired performance, ${ }^{7}$ whilst clinical techniques can be utilised where specific problems are indicated. ${ }^{7}$

\section{SURVEILLANCE IS LIKELY TO FURTHER THE} PROTECTION OF THE HEALTH OF EMPLOYEES As with many sportspeople, footballers often fail to report the presence of minor injuries through ignorance of the long term effects or fear of the effect it might have on their future team selection and long term career prospects. Continued play whilst suffering from some minor injuries can lead to repeated minor acute injuries followed eventually by severe chronic injury. By definition, health surveillance cannot provide total protection because the monitoring process detects conditions that are already present; however, it is an intervention procedure that enables steps to be taken at an early stage to remedy conditions or reduce the risk of further deterioration. This can be achieved by, for example, medical intervention or a modification to a fitness training programme.

Developing a health surveillance strategy A health surveillance strategy should have defined aims and objectives to identify and protect individuals at risk. Relevant adverse health conditions should therefore be identified and recorded with appropriate tests defined to indicate the onset of the conditions. The timing and frequency of testing should be appropriate to the potential health risks. Aspects that should be considered for inclusion in a health surveillance programme for footballers include benchmarking player fitness through pre-recruitment, pre-season, duringseason, post-season, and post-rehabilitation assessments and defining criteria for action. A range of approaches and techniques can be used for gathering information, e.g. questions, inspection by a physiotherapist or doctor, and measurement of physiological parameters by the physiotherapist. This information should be recorded and reviewed on a regular basis by the club physiotherapist and when appropriate by a doctor.

Two examples of how a surveillance approach can be used are: (1) a modified Romberg test, which provides early evaluation of functional instability of the ankle; if instability is indicated, muscle strengthening is recommended using an ankle $\operatorname{disc}^{7}$; (2) muscle strength tests using an isokinetic dynamometer, which can indicate the potential for muscular tendon injuries arising from an imbalance between quadriceps and hamstrings; muscle strengthening exercises reduce the potential for injury. ${ }^{1}$

\section{Conclusions}

A physiological profile provides a benchmark of a player's overall fitness and standards against which players can be monitored for the onset of injury and the assessment of fitness to play after injury and rehabilitation. Performance tests for players, against their benchmark standards, also provide records to demonstrate that players have been passed fit and have not been subjected to undue risk by an early return to play. These records may be of particular use in the defence of a civil claim brought by a player who has suffered chronic injury. Club officials should understand that to encourage or allow a player to continue to play whilst suffering from an injury, which could lead to a further deterioration in condition, is condoning an unsafe practice; as such there is a breach of health and safety legislation.

In discussing the consequences of spinal injuries in rugby, Hamlyn ${ }^{8}$ commented "To merely surround any sport with doctors but provide no data to support their work serves only to make things look better. Good medicine is based on sound data. The collection of this data may be difficult but the prize will be worth it". Developing health surveillance strategies in professional football is a basis on which meaningful data can be collected for the benefit of the sport, the clubs, and, above all, the players.

1 Renstrom P. An introduction to chronic overuse injuries. In Harries $\mathrm{M}$, et al, eds. Oxford textbook of sports medicine. Harries M, et al, eds. Oxford textbook of sports

2 Fuller CW. Implications of health and safety legislation for the professional sportsperson. Br $\mathcal{F}$ Sports Med 1995;29:59.

3 Management of Health and Safety at Work Regulations 1992. London: HMSO, SI 1992, No 2051.

4 Ekstrand J. Injuries. In: Ekblom B, ed. Football (soccer) Oxford: Blackwell Scientific Publications, 1994:175-94.

5 Nisse J. Sport counts the cost of accidents waiting to happen. The Times 1996 Aug 5:18.

6 Hodson A. Too much too soon? Sportcare fournal 1994;1:

7 Ekstrand J. Injury prevention. In: Ekblom B, ed. Football

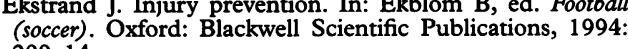
209-14

8 Hamlyn P. Rugby spinal injury fears remain. Daily Telegraph 1995 May 31:38. 